九州大学学術情報リポジトリ

Kyushu University Institutional Repository

Larvae of the Weevil Family Curculionidae of Japan Part 3. Ramphinae to Curculioninae (Insecta:Coleoptera)

Lee, Chang-Young

Entomological Laboratory, Faculty of Agriculture, Kyushu University

Morimoto, Katsura

Entomological Laboratory, Faculty of Agriculture, Kyushu University

https://doi.org/10.5109/24115

出版情報: 九州大学大学院農学研究院紀要. 40 (3/4)，pp.287-306，1996-03. Kyushu University バージョン：

権利関係 : 


\title{
Larvae of the Weevil Family Curculionidae of Japan Part 3. Ramphinae to Curculioninae (Insecta:Coleoptera) ${ }^{1)}$
}

\section{Chang-Young Le $\mathrm{L}^{2)}$ and Katsura Morimoto}

\author{
Entomological Laboratory, Faculty of Agriculture, \\ Kyushu University, Fukuoka 812-81, Japan \\ (Received October 26, 1995)
}

\begin{abstract}
In continuation of our studies on the weevil larvae of Japan from Vol. 33, p. 152 of this Journal, third part of the family Curculionidae deals with 22 species of the the genera Ixalma, Rhynchaenus, Ramphus, Echinocnemus, Endaeus, Derelomus, Anthonomus, a nd Curculio. All of them are described in detail with illustrations. Methods and terminology we employed are the same as already noted in our previous paper on the Anthribiae in Vol. 31, p. 71 of this Journal. 1987.
\end{abstract}

\section{Genus Ixalma Pascoe}

(Figs. 1- 2)

Ixalma hilleri: Hayashi, 1959, Ill. Ins. Larv. Jpn., : 527, fig. 995.

Ixalma nigriventris: Morimoto, 1984, Esakia, (22) : 7.

Body more slender, setae minute.

Head retracted, deeply and broadly emarginate at posterior margin, frontal piece pointed and reaching occipital foramen. Anterior ocellus present. Antenna with apical segment short, basal segment cushion-like with small elongate sensory appendages. Catapophyses in same plane as frons. Hypopharyngeal bracon absent. Frontal suture distinct. Endocarina long and reaching posteriorly far beyond posterior margin of epicranial halves in middle. Frons with three pairs of setae. Dorsal epicranium with five setae, setae 1 and 2 short, subequal, setae 3, 4 and 5 long, subequal. Lateral epicranial seta 1 short, 2 moderately long. Ventral epicranial setae absent. Clypeal setae minute. Anterior margin of labrum weakly trilobed. Labral seta 1 absent, 2 longer than 3. Median and paired minute lateral sensilla present. Labral rods moderately long, subparallel. Epipharynx with three anterolateral setae arrange on a line obliquely backward towards the middle, four anteromedian setae and four median spines, the latter thick and almost as long as innermost anterolateral seta. Epipharyngeal sensory pores in two clusters, three in each cluster, between anterior median spines. Epipharynx without asperities. Mandible with two apical teeth. Mandibular seta 1 short, slightly longer than and directly behind 2. Labial palpus with two segments, widely separated. Premental sclerite incomplete, premental seta absent. Postmentum with one pair of setae. Maxillary palpus with two segments, basal segment with two sensilla and one very short lateral seta, apical

1) Contribution from the Entomological Laboratory, Faculty of Agriculture, Kyushu University, Fukuoka (Ser. 4, No.105).

2) Present address: Department of Forest Resources Protection, College of Forestry, Kangweon National University, Chuncheon 200-701, Korea. 


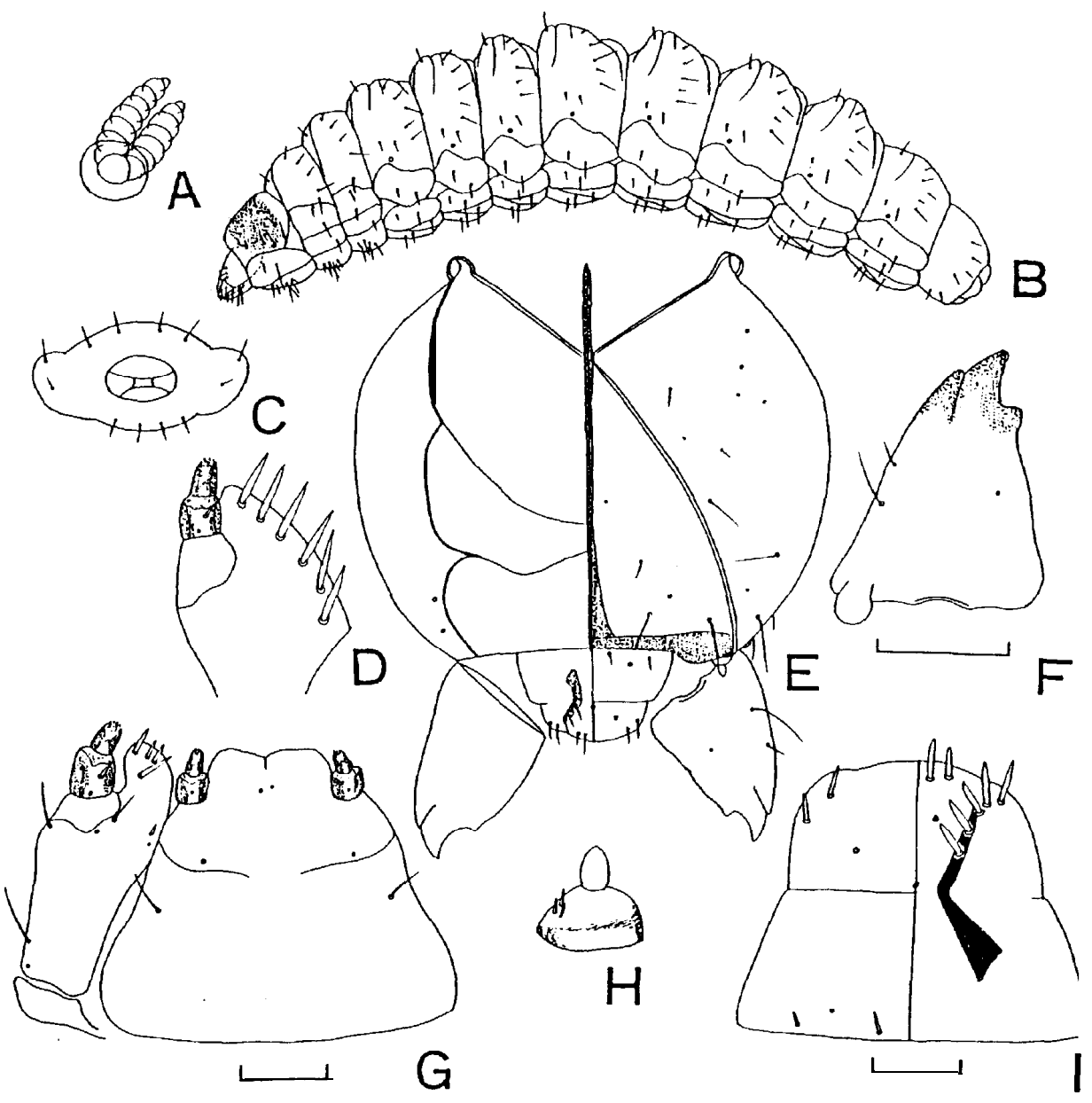

Fig. 1. Ixalma nigriventris Kôno

A: Spiracle. B: Mature larva. C: Anus. D: Maxilla, dorsal. E: Head. F: Mandible G: Maxilla and labium. H: Antenna. I: Labrum and epipharynx. Scale: $0.05 \mathrm{~mm}$.

segment without seta. Mala with four ventral and six or seven dorsal setae.

Pronotum with seven or nine setae, with a transverse pigmented smooth plate. Thoracic spiracle bicameral. Prodorsum of meso- and metathorax with one short seta. Postdorsum of meso- and metathorax with four setae, setae moderately short. Alar area with one short seta. Spiracular area with one short seta. Epipleurum with one seta. Pleurum of meso- and metathorax with one seta. Pedal area with seven short setae, sternal seta subequal to eusternal seta.

Abdomen with eight pairs of spiracles. Spiracle all lateral, bicameral. Typical 


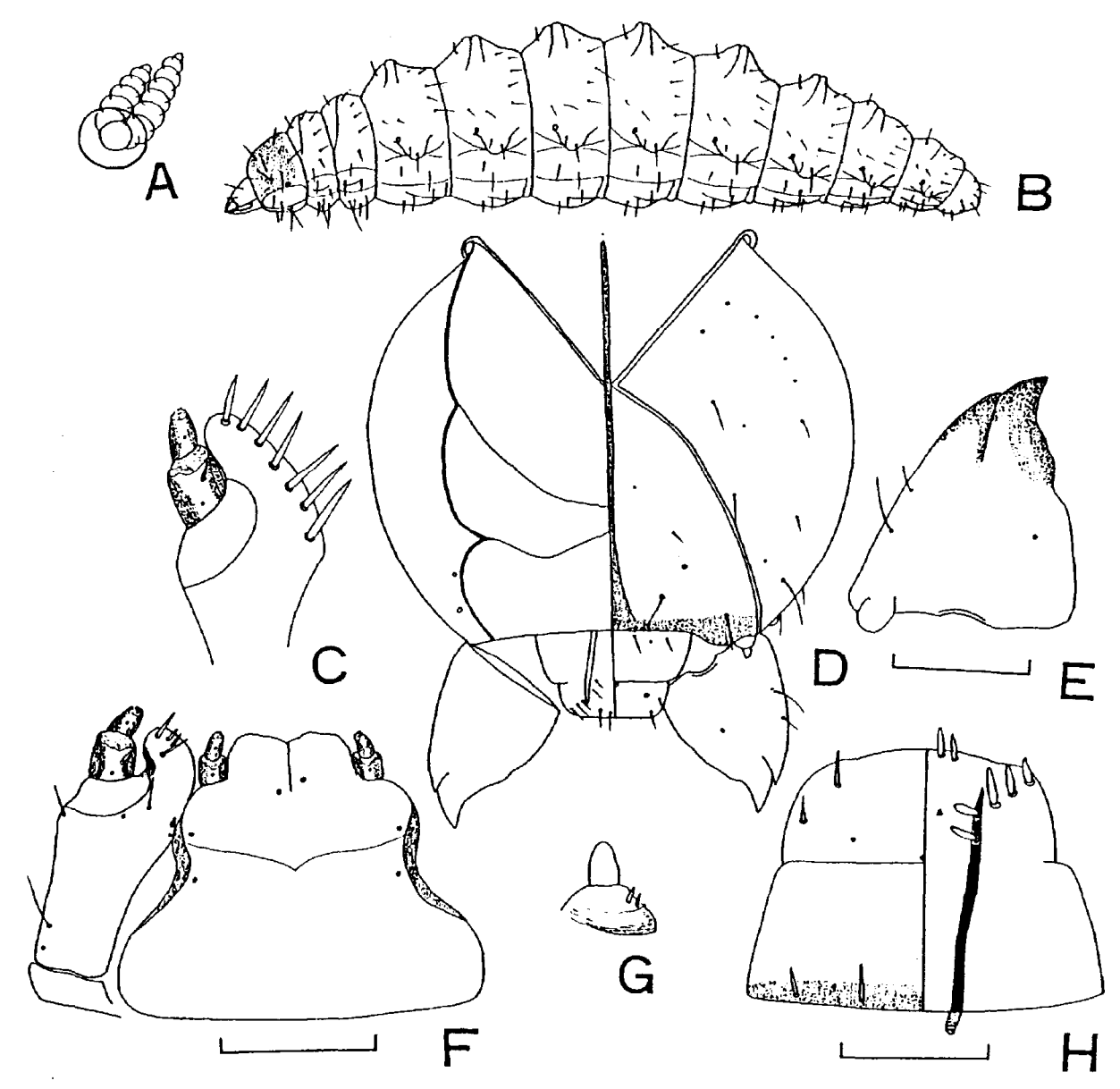

Fig. 2. Ixalma hilleri Roelofs

A: Spiracle. B: Mature larva. C: Maxilla, dorsal. D: Head. E: Mandible.

F: Maxilla and labium. G: Antenna. H: Labrum and epipharynx. Scale: $0.05 \mathrm{~mm}$.

abdominal segments with three weak dorsal folds. First to seventh abdominal segments convex dorsally, ninth abdominal segment subconical. Prodorsum with a seta. Postdorsum with five setae, setae 1, 2 and 4 short, subequal, 3 and 5 long, subequal. Spiracular area with two setae, seta 1 very short, seta 2 short. Epipleurum with two setae, one short, the other slightly longer. Pleurum with two setae, one short, the other slightly longer. Pedal area with one short seta. Eusternum with two very short setae. Anus terminal, with four lobes. 
Species and materials examined.

Ixalma nigriventris Kôno. Makiyama, Kochi Pref., 29. viii. 1954, leaf-miner of Euptelaea polyandra. (Fig. 1)

Ixalma hilleri Roelofs. Hikosan, Fukuoka Pref., 8. xi.1953, leaf-miner of Kadsura japonica. (Fig. 2)

\section{Genus Rhynchaenus Clairville \& Schellenberg}

(Figs. 3- 5)

Rhynchaenus: Emden, 1938, Trans. Roy. Ent. Soc. London, 87: 22.

Body subcircular in cross-section, skin with subacute granules, setae minute.

Head retracted, deeply and broadly emarginate at posterior margin, frontal piece pointed and about reaching occipital foramen. Anterior ocellus present. Antenna with apical segment longer than wide, basal segment cushion-like with small elongate sensory appendages. Catapophyses in same plane as frons. Hypopharyngeal bracon absent. Forntal suture distinct. Endocarina long and reaching posteriorly far beyond posterior margin of epicranial halves in middle. Frons with one or two setae. Dorsal epicranium with one or two setae. Lateral epicranial seta 1 minute, 2 moderately long. Ventral epicranial setae minute. Clypeal seta 1 short to moderately long, nearly twice as long as 2. Anterior margin of labrum transverse. Labral setae 1 and 2 short to moderately long, nearly twice as long as 3. Labral rods short and stout. Epipharynx with three anterolateral setae, six anteromedian setae and four median blade-like spines. Epipharyngeal sensory pores in two clusters, three in each cluster, a little before the level of anterior spines. Mandible with two apical teeth. Mandibular seta 1 short, slightly longer than and directly behind 2. Labial palpus with one segment, widely separated, longer than wide. Premental sclerite incomplete. Postmenturn broadly pigmented, with three setae. Maxillary palpus with two segments, basal segment with two sensilla and one very short lateral seta, apical segment without seta. Mala with three ventral and five to seven dorsal setae.

Pronotum with seven or eight setae and a transverse pigmented smooth plate. Thoracic spiracle bicameral. Prodorsum of meso- and metathorax with a short seta. Postdorsum of meso- and metathorax three or four short setae. Alar area with one short seta. Spiracular area with one short seta. Epipleurum with one seta. Pleurum of mesoand metathorax with one seta. Pedal area with five to seven short setae. Most ventral seta of pedal area subequal to very short sternal seta. Sternal setae subequal to eusternal setae. Prosternum broadly pigmented.

Abdomen with eight pairs of spiracles. Spiracles all lateral, bicameral. Typical abdominal segments with three weak dorsal folds. First to seventh abdominal segment convex dorsally, ninth and tenth abdominal segments conjointly tapering posteriorly. Prodorsum with one short seta. Postdorsum with three or five setae, setae moderately short. Spiracular area with one or two short setae. Epipleurum with two moderately short setae. Pleurum with two moderately short setae. Pedal area with one short seta. Eusternum with two very short setae. Anal segment conical. 
Key to species examined

1. Head dark brown, prosternum with distinct three brownish patches

-. Head pale brown to yellowish brown, prosternum at most with pale smooth areas ...... 3

2. Epicranium with mesh-like structure behind the middle ........ Rhynchaenus miyatakei

-. Epicranium without such structure Rhynchaenus japonicus

3. Prosternum without smooth pale area Rhynchaenus cylindricus

-. Prosyernum with pale smooth area Rhynchaenus horii

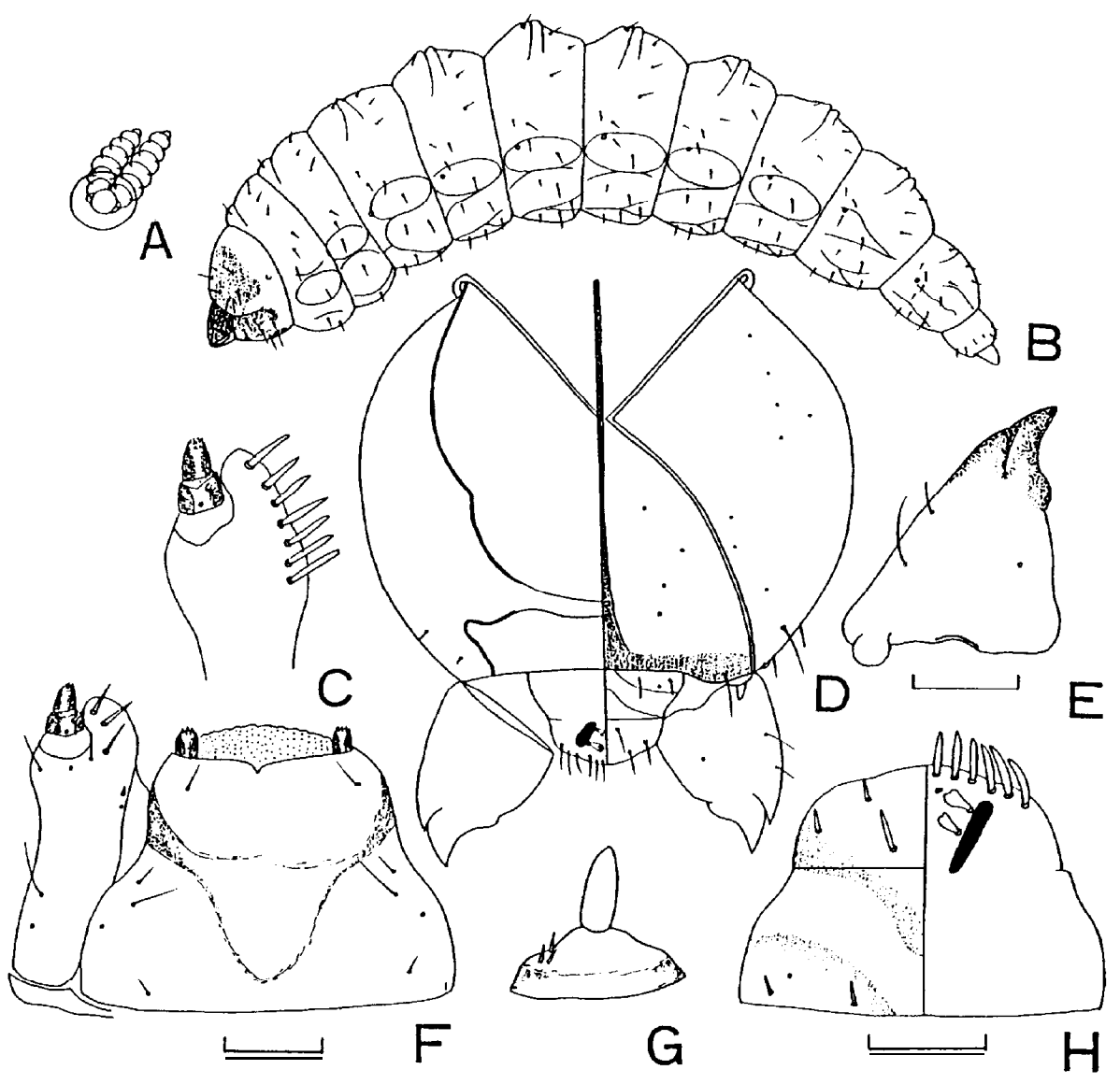

Fig. 3. Rhynchaenus japonicus Hustache

A: Spiracle. B: Mature larva. C: Maxilla, dorsal. D: Head. E: Mandible.

F: Maxilla and labium. G: Antenna. H: Labrum and epipharynx. Scale: 0.05mm. 


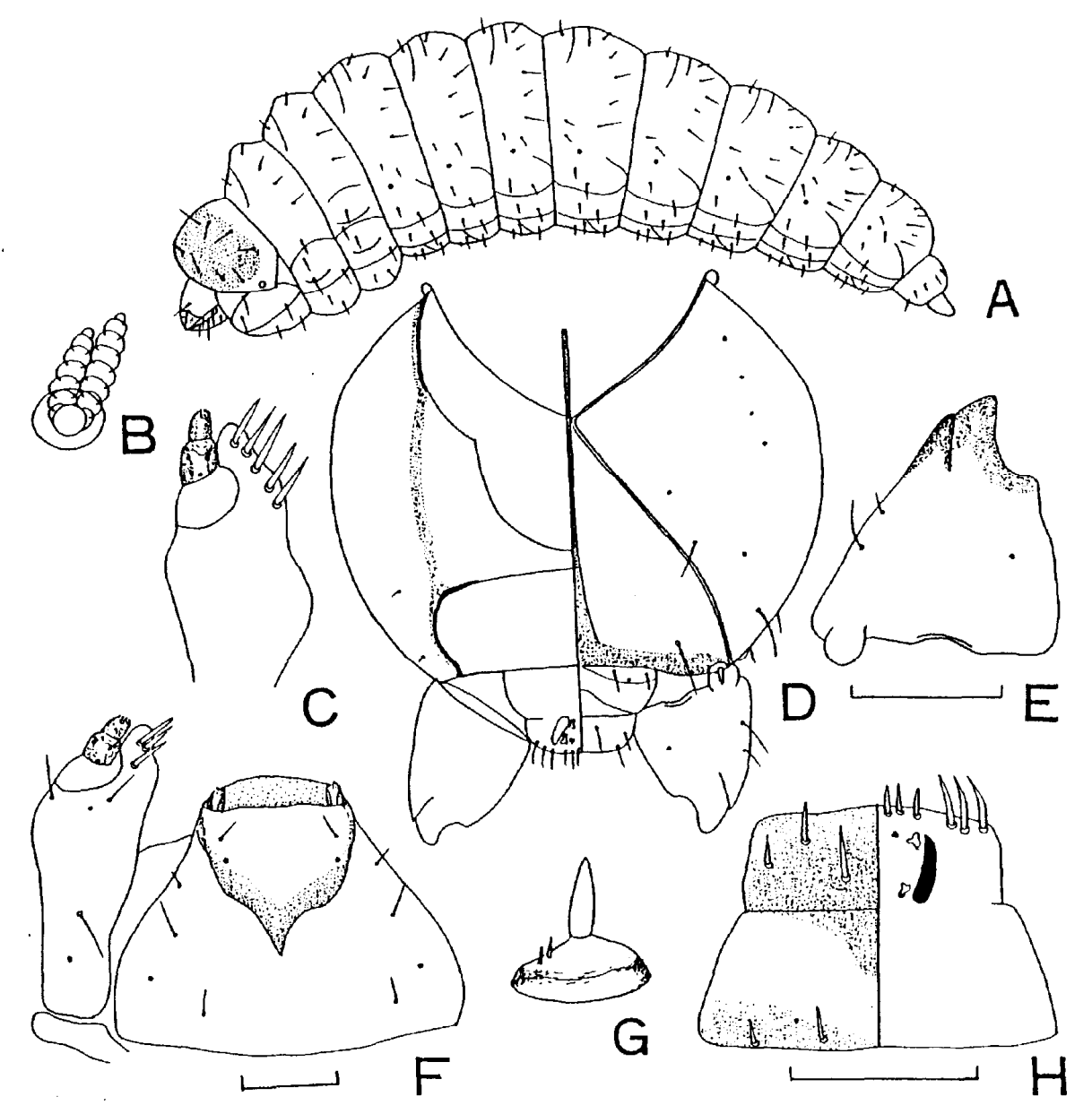

Fig. 4. Rhynchaenus cylindricus Morimoto

A: Mature larva. B: Spiracle. C: Maxilla, dorsal. D: Head. E: Mandible.

F: Maxilla and labium. G: Antenna. H: Labrum and epipharynx. Scale: $0.05 \mathrm{~mm}$.

Species and materials examined.

Rhynchaenus japonicus Hustache. Gunma Pref., 9. v. 1983, leaf-miner of Quercus dentata and serrata. (Fig.3)

Rhynchaenus horii Kôno. Nata, Fukuoka City, 5. v. 1981, leaf-miner of Celtis sinensis Rhynchaenus cylindricus Morimoto. Mt.Yachirodake, Nagasaki Pref., 19. v. 1983, borer of leaf midrib of Pasania edulis. (Fig.4)

Rhynchaenus miyatakei Morimoto. Nagai Park, Osaka City, 24. v. 1984, leaf-miner of Pterocarya stenoptera. (Fig.5) 


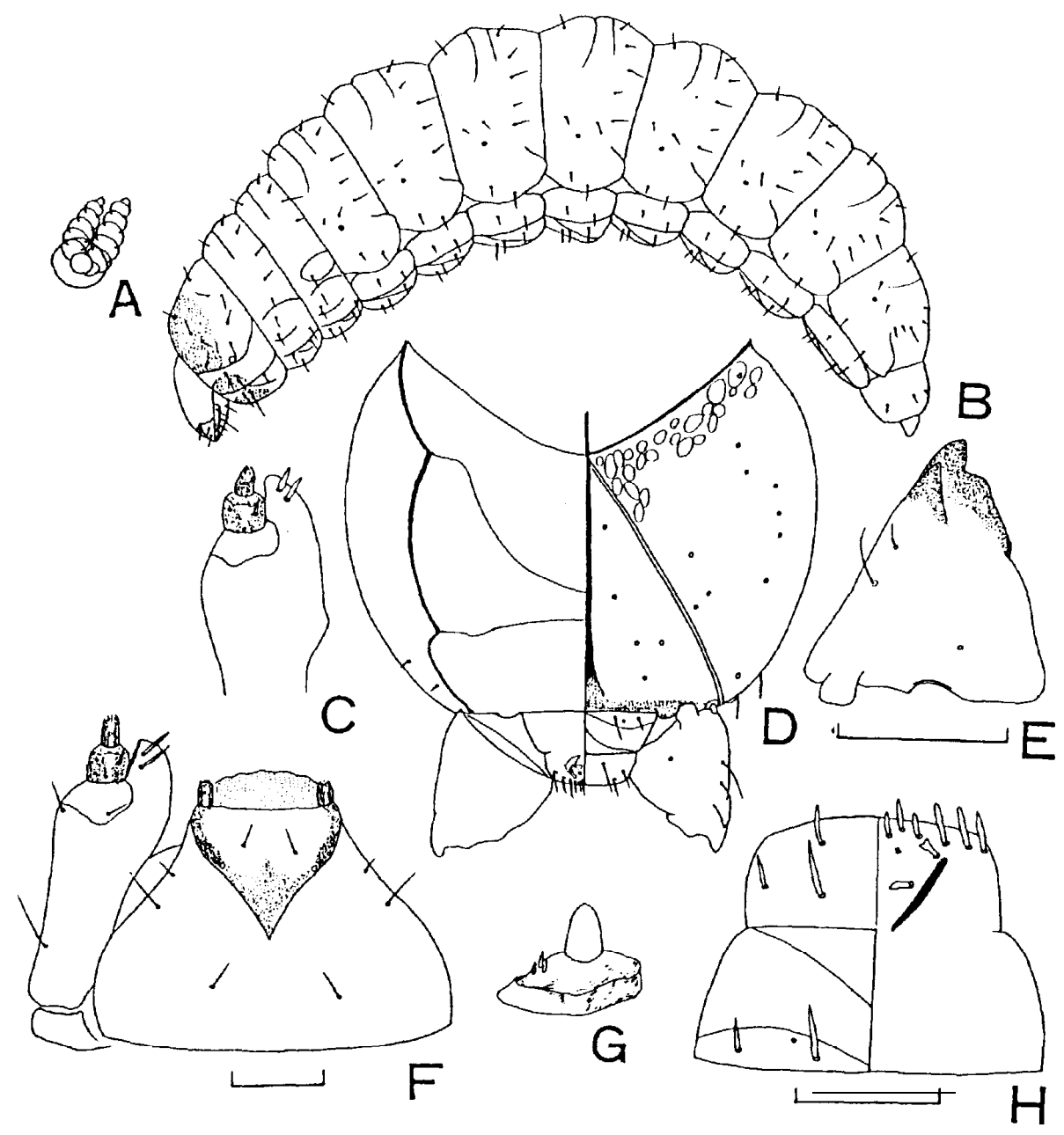

Fig. 5. Rhynchaenus miyatakei Morirnoto

A: Spiracle. B: Mature larva. C: Maxilla, dorsal. D: Head. E: Mandible.

F: Maxilla and labium. G: Antenna. H: Labrum and epipharynx. Scale: $0.05 \mathrm{~mm}$.

\section{Genus Ramphus Clairville}

Rhamphus:Emden, 1938, Trns. Roy. Ent. Soc. London, 87: 22.

\section{Ramphus hisamatsui Chûjô et Morimoto}

(Fig. 6) 
Body flattened dorso-ventrally. Skin asperities mainly blunt granules, especially near middle of dorsal surface.

Head retracted, deeply and broadly emarginate at posterior margin, frontal piece pointed and about reaching occipital foramen. Anterior ocellus present. Antenna with apical segment longer than wide, basal segment cushion-like with small elongate sensory appendages. Catapophyses in same plane as frons. Hypopharyngeal bracon absent. Frontal suture distinct. Endocarina long and reaching posteriorly far beyond posterior margin of epicranial halves in middle. Frons with one pair of setae. Dorsal epicranial

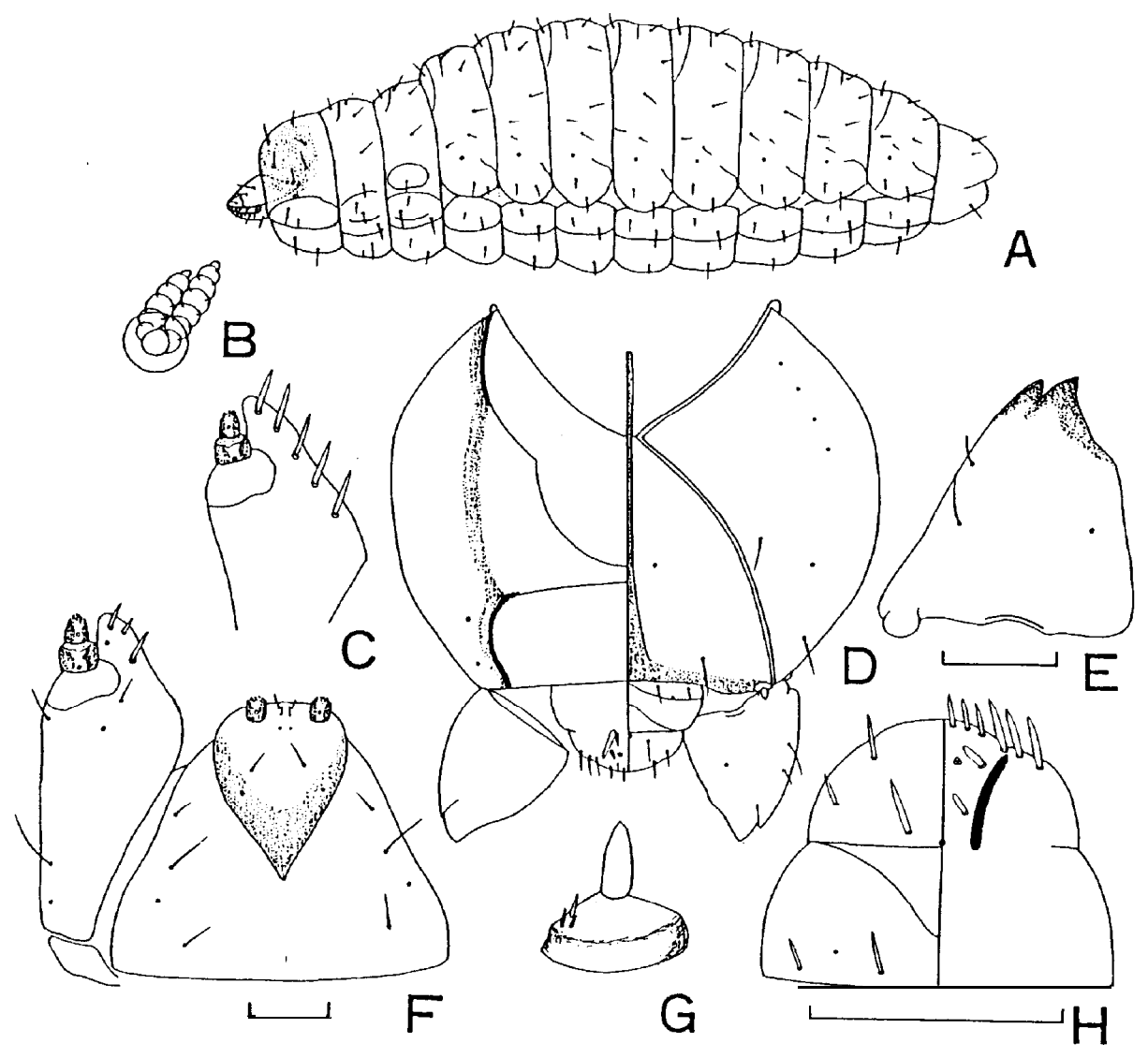

Fig. 6. Rhamphus hisamatsui Chûjô et Morimoto

A: Mature larva. B: Spiracle. C: Maxilla, dorsal. D: Head. E: Mandible.

F: Maxilla and labium. G: Antenna. H: Labrum and epipharynx. Scale: $0.05 \mathrm{~mm}$ 
setae 3 and 5 long, subequal, 1, 2 and 4 absent. Lateral epicranial setae absent. Ventral epicranial setae absent. Four minute posterior epicranial setae present. Clypeal seta 1 short to moderately long, nearly twice as long as 2 . Anterior margin of labrum weakly trilobed, posterior margin extended medially. Labral setae 1 and 2 short to moderately long, nearly twice as long as 3. Median sensilla present on labrum. Labral rods short and rather narrow, subparallel. Epipharynx with three anterolateral setae, six anteromedian setae and four median spines. Epipharyngeal sensory pores in two clusters, three in each cluster, between anterior spines. Epipharynx without asperities. Mandible with two sharp apical teeth, as long as wide. Mandibular seta 1 short, slightly long than and directly behind 2. Labial palpus with one segment. Premental sclerite complete. Postmenturn not pigmented, with three setae on each side in a straight line. Maxillary palpus with two segments, basal segment with two sensilla and one very short lateral seta, apical segment without seta. Mala with three ventral and five dorsal setae.

Pronotum with six setae and a transverse pigmented smooth plate. Thoracic spiracle bicameral. Prodorsum of meso- and metathorax with one short seta. Postdorsum of meso- and metathorax with three short setae. Alar area with one short seta. Spiracular area with one short seta. Alar area with one short seta. Pleurum of meso-and metathorax with one seta. Pedal area with two short setae.

Abdomen with eight pairs of spiracles. Spiracles all lateral, bicameral. Typical abdominal segments with three dorsal folds. Prodorsum with one short seta. Postdorsum with three setae, setae moderately short. Spiracular area with two short setae. Epipleurum with two short setae. Pleurum with two short setae. Pedal area with one short seta. Eusternum without setae. Anus terminal, with four lobes.

Width of head. $0.3 \mathrm{~mm}$.

Materials examined. Mt. Hikosan, Fukuoka Pref., 20. x. 1956, leaf-miner of Acer mono.

\section{Echinocnemus squameus (Billberg)}

(Fig. 7)

Body slender, subcircular in cross-section, setae minute.

Head free, circular in outline, longer than wide. Anterior ocellus present. Antenna with rather stout conical segment, distinctly longer than wide. Catapophyses in same plane as frons. Hypopharyngeal bracon readily discernible. Frontal suture distinct. Endocarina absent. Frons with two setae, setae 1, 2 and 3 absent. Dorsal epicranial setae 1, 3 and 5 long, subequal, 2 and 4 short, subequal. Lateral epicranial seta 1 moderately long, 2 long. Ventral epicranial setae 1 and 2 short to moderately long, subequal. Four minute posterior epicranial setae present. Clypeal seta 1 short to moderately long, nearly twice as long as 2. Anterior margin of labrum trilobed. Labral setae 1 and 2 short to moderately long, nearly twice as long as 3 . Median and paired lateral sensilla present on labrum. Labral rods moderately elongate, subparallel. Epipharynx with three anterolateral setae, six anteromedian setae and four median spines. Epipharyngeal sensory pores absent. Mandible with two apical teeth. Mandibular seta 1 short, slightly longer than and directly behind 2. Labial palpus with two segments, Premental sclerite 
indistinct. Postmentum with one pair of setae, setae 1, and 3 absent. Maxillary palpus with two segments, basal segment with two sensilla and one very short lateral seta, apical segment without seta. Mala with three ventral and three dorsal setae.

Pronotum with eight setae. Thoracic spiracle with paired dorsal air-tubes projecting well beyond peritreme,thorn-like. Prodorsum of meso- and metathorax with one short seta. Postdorsum of meso- and metathorax with four setae, setae moderately short. Alar area with one short seta. Spiracular area with one short seta. Epipleurum with one seta. Pleurum of meso- and metathorax with one seta. Pedal area with seven setae, setae

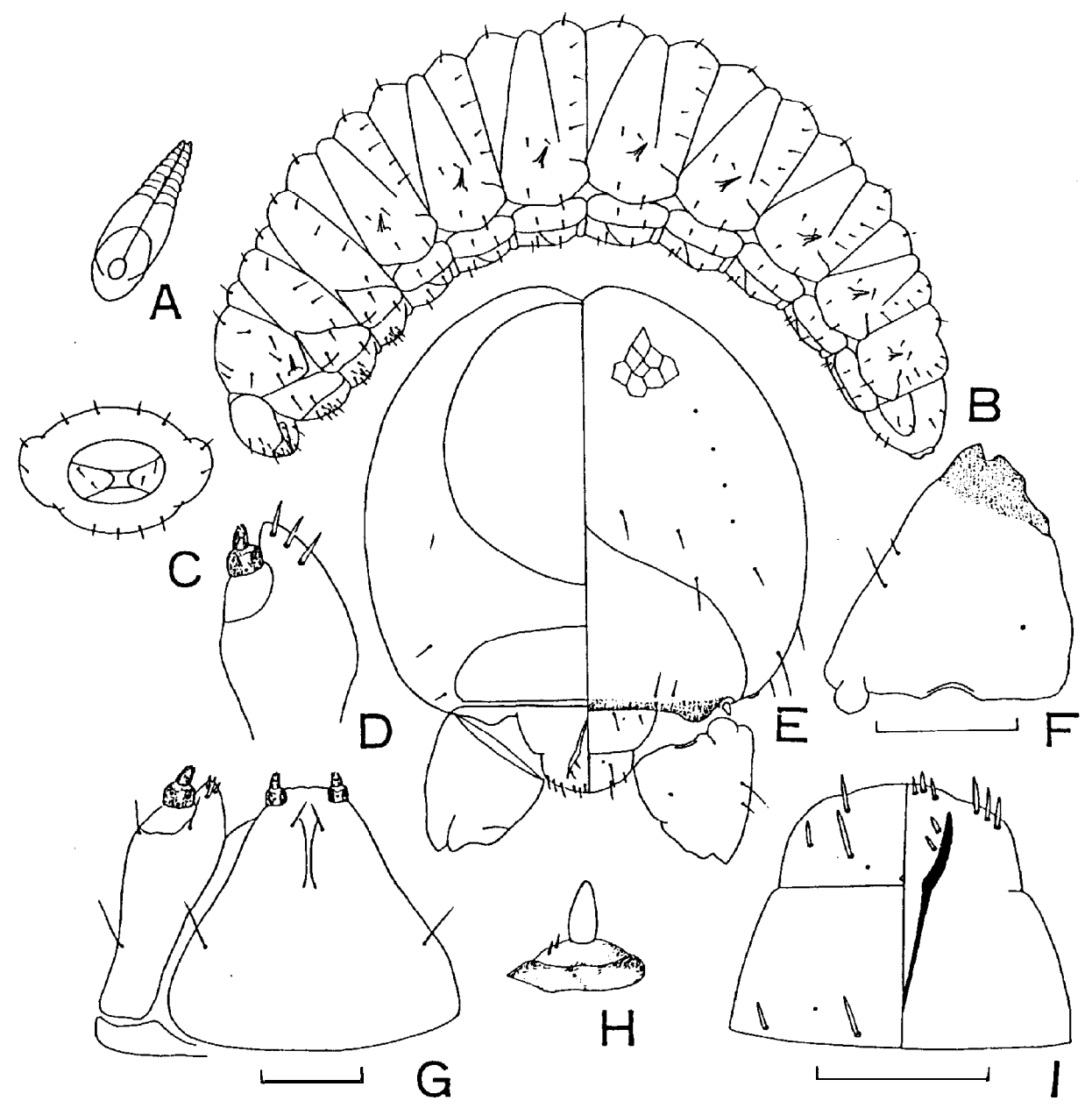

Fig. 7. Echinocnemus squameus (Billberg)

A: Spiracle. B: Mature larva. C: Anus. D: Maxilla, dorsal. E: Head. F: Mandible G: Maxilla and labium. H: Antenna. I: Labrum and epipharynx. Scale: $0.1 \mathrm{~mm}$. 
moderately short. Most ventral setae of pedal area subequal to very short sternal seta. Sternal setae subequal to eusternal setae.

Abdomen with eight pairs of spiracles. Spiracles all lateral, bicameral, paired dorsal air-tubes projecting well beyond peritreme, thorn-like. Typical abdominal segments with three dorsal folds. Prodorsum with one short seta. Postdorsum with five setae, setae 1, 2 and 4 short, subequal, 3 and 5 long, subequal. Spiracular area with two setae, setae moderately short. Epipleurum with two setae, one short, the other slightly longer. Pleurum with two setae, one short, the other slightly longer. Pedal area with one short seta. Eusternum with two very short setae. Sternellum present. Anus terminal, with four lobes.

Width of head $0.6 \mathrm{~mm}$.

Materials examined. Akita Pref., injurious to rice in the pady field.

\section{Endaeus sp.}

(Fig. 8)

Body narrow and moderately curved.

Head retracted, deeply and broadly emarginate at posterior margin, as long as wide. Anterior ocellus present. Antenna with a rather stout conical segment, distinctly longer than wide. Catapophyses in same plane as frons. Hypopharyngeal bracon present. Frontal suture distinguishable throughout its length, incomplete anteriorly. Endocarina distinct. Frons with four pairs of setae, setae 4 and 5 long, 1 and 3 short, subequal, 2 absent. Dorsal epicranial setae 1, 3 and 5 long, subequal, 2 and 4 short, subequal. Lateral epicranial seta 1 moderately long, 2 long. Ventral epicranial setae short to moderately long, subequal. Four minute epicranial setae present. Clypeal seta 1 short to moderately long, nearly twice as long as 2. Anterior margin of labrum trilobed. Labral setae 1 and short to moderately long, nearly twice as long as 3. A pair of lateral sensilla present on labrum. Labral rods moderately elongate, short, subparallel. Epipharynx with three anterolateral setae, six anteromedian setae and four median spines. Epipharyngeal sensory pores in two clusters, three in each cluster, before the anterior spines. Mandible with two apical teeth, as long as wide. Mandibular seta 1 short, slightly longer than and directly behind 2. Labial palpus with two segments. Premental sclerite incomplete, well sclerotized at sides, slightly pigmented in middle. Postmenturn with three pairs of setae, posterior pair separated by a distance approximately one-half as great as that between setae of middle pair. Maxillary palpus with two segments, basal segment with two sensilla and one very short lateral seta, apical segment without seta. Mala with four ventral and seven dorsal setae.

Pronotum with nine setae. Thoracic spiracle bicameral. Prodorsum of meso- and metathorax with one short seta. Postdorsum of meso- and metathorax with four setae, setae 1 and 2 short, subequal, 3 and 4 moderately long, subequal. Alar area with one short seta. Spiracular area with one seta. Epipleurum with one seta. Pleurum of prothorax with two setae, of meso- and metathorax with one seta. Pedal area with six setae, one moderately long, the remainder shorter and subequal to sternal seta. Sternal setae subequal to eusternal setae. 


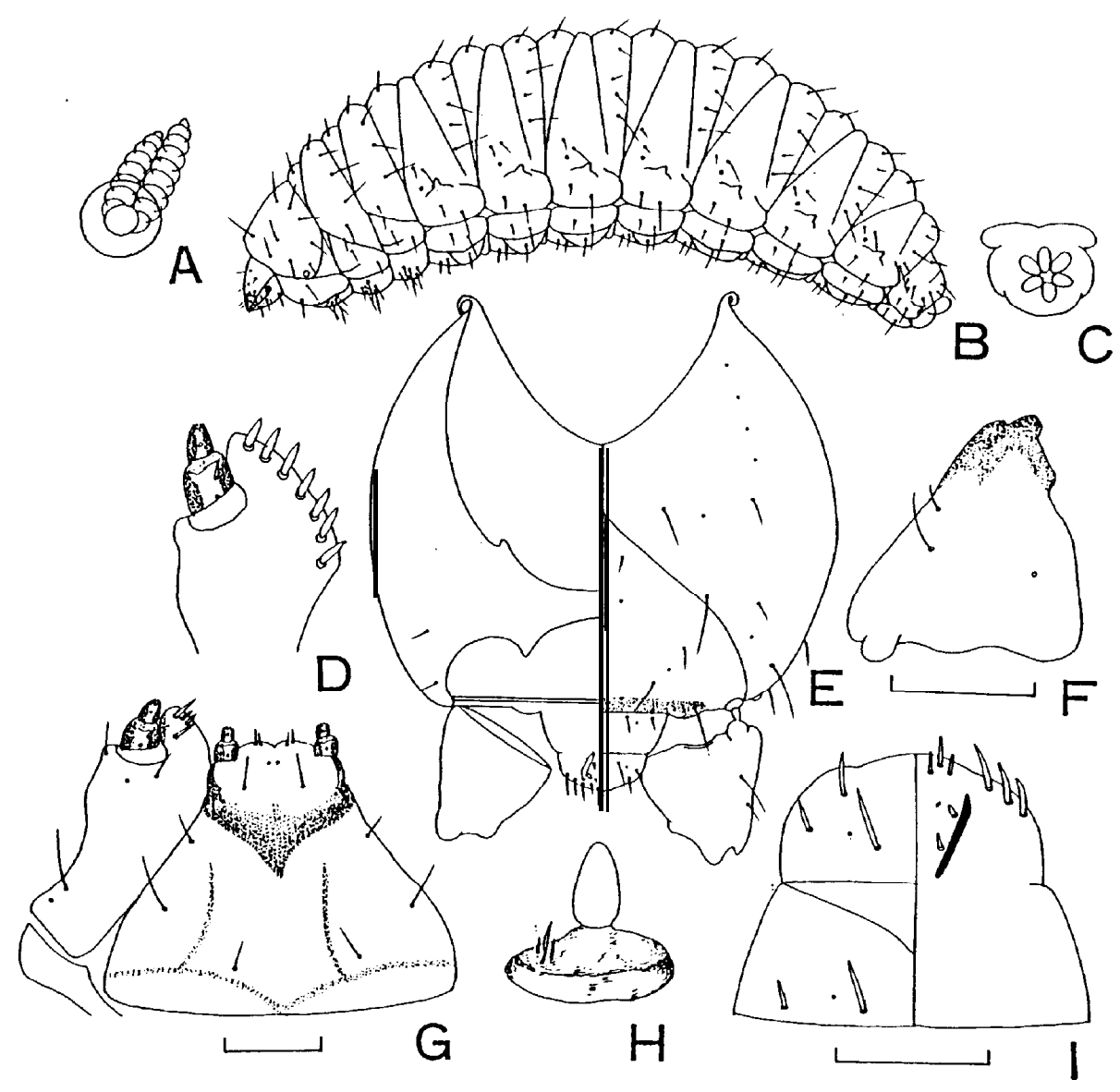

Fig. 8. Endaeus sp.

A: Spiracle. B: Mature larva. C: Anus. D: Maxilla, dorsal. E: Head. F: Mandible

G: Maxilla and labium. H: Antenna. I: Lahrum and epipharynx. Scale: $0.05 \mathrm{~mm}$.

Abdomen with eight pairs of spiracles. Spiracles all lateral, bicameral. Typical abdominal segments with three dorsal folds. Prodorsum with one short seta. Postdorsum with five setae, 1, 3 and 5 moderately long, subequal, 2 and 4 short, subequal. Spiracular area with two setae, seta 1 very short, 2 short. Epipleurum pointed laterally, with two setae, one short, the other slightly longer. Pleurum with two setae, one short, the other slightly longer. Pedal area with one short seta. Eusternum with two very short setae. Sternellum present. Anus terminal, surrounded by six fleshy knobs.

Width of head $0.4 \mathrm{~mm}$. 
Material examined. Mt. Hikosan, Fukuoka Pref., 18. v.1955, leaf-miner of

Rhododendron spp.

\section{Derelomus uenoi Morimoto}

(Fig. 9)

Derelomus uenoi: Morimoto, 1959, Entom. Rev. Japan, 10: 47.

Body moderately short and stout, length about $3 \mathrm{~mm}$.

Head free, unicolored brown, as long as wide. Anterior ocellus present, posterior ocellus absent. Antenna with a conical segment and several minute setae. Catapophyeses in same plane as frons. Hypopharyngeal bracon readily discernible. Frontal suture distinct. Endocarina absent. Frons with four pairs of setae, setae 4 and 5 long, subequal, 1 and 3 short, subequal, seta 2 absent. Dorsal epicranial setae 1, 3 and 5 long, subequal, 2 moderately long, 4 short. Lateral epicranial seta 1 moderately long, 2 long. Ventral epicranial setae short to moderately long, subequal. Four minute posterior epicranial setae present. Clypeal seta 1 short to moderately long, nearly twice as long as 2 . Anterior margin of labrum trilobed. Labral setae 1 and 2 short to moderately long, nearly twice as long as 3. Paired lateral sensilla present on labrum. Labral rods moderately stout, subparallel. Epipharynx with three anterolateral setae, six anteromedian setae and four median spines. Epipharyngeal sensory pores in two clusters, two in each cluster, a little anterior to the level of anterior spines. Mandible with two apical teeth, slightly longer than wide. Mandibular seta 1 short, slightly longer than and directly behind 2. Labial palpus with two segments, apical and basal segment longer than wide. Premental sclerite complete, with anterior and posterior median extensions. Postmentum with three pairs of setae, posterior pair separated by a distance those of middle pair. Maxillary palpus with two segments, basal segment with two sensilla and one very short lateral seta, apical segment without seta. Mala with five ventral and six to seven dorsal setae.

Pronotum with ten setae. Thoracic spiracle bicameral. Prodorsum of meso- and metathorax with one short seta. Postdorsum of meso- and metathorax with four setae, setae 1 and 2 short, subequal, 3 and 4 moderately long, subequal. Alar area with one short seta. Spiracular area with one seta. Epipleurum with one seta. Pleurum of prothorax with two setae, of meso- and metathorax with one seta. Pedal area with six setae, two moderately long, the remainder short and subequal to short sternal seta. Sternal setae subequal to eusternal setae.

Abdomen with eight pairs of spiracles. Spiracles all lateral, bicameral. Typical abdominal segments with three dorsal folds. Prodorsum with a moderately long seta.

Postdorsum with five setae, 1, 2 and 4 short, subequal, 3 and 5 moderately long, subequal. Spiracular area with two setae, seta 1 very short, seta 2 short. Epipleurum with two setae, one short, the other slightly longer. Pleurum with two setae, one short, the other slightly longer. Pedal area with one short seta. Eusternum with two very short setae. Sternellum present. Anus terminal, surrounded by eight fleshy knobs.

Width of head. $0.8 \mathrm{~mm}$.

Materials examined. Kitashirakawa, Kyoto City, vii. 1958, from rachis of Trachycarpus excelsa. 


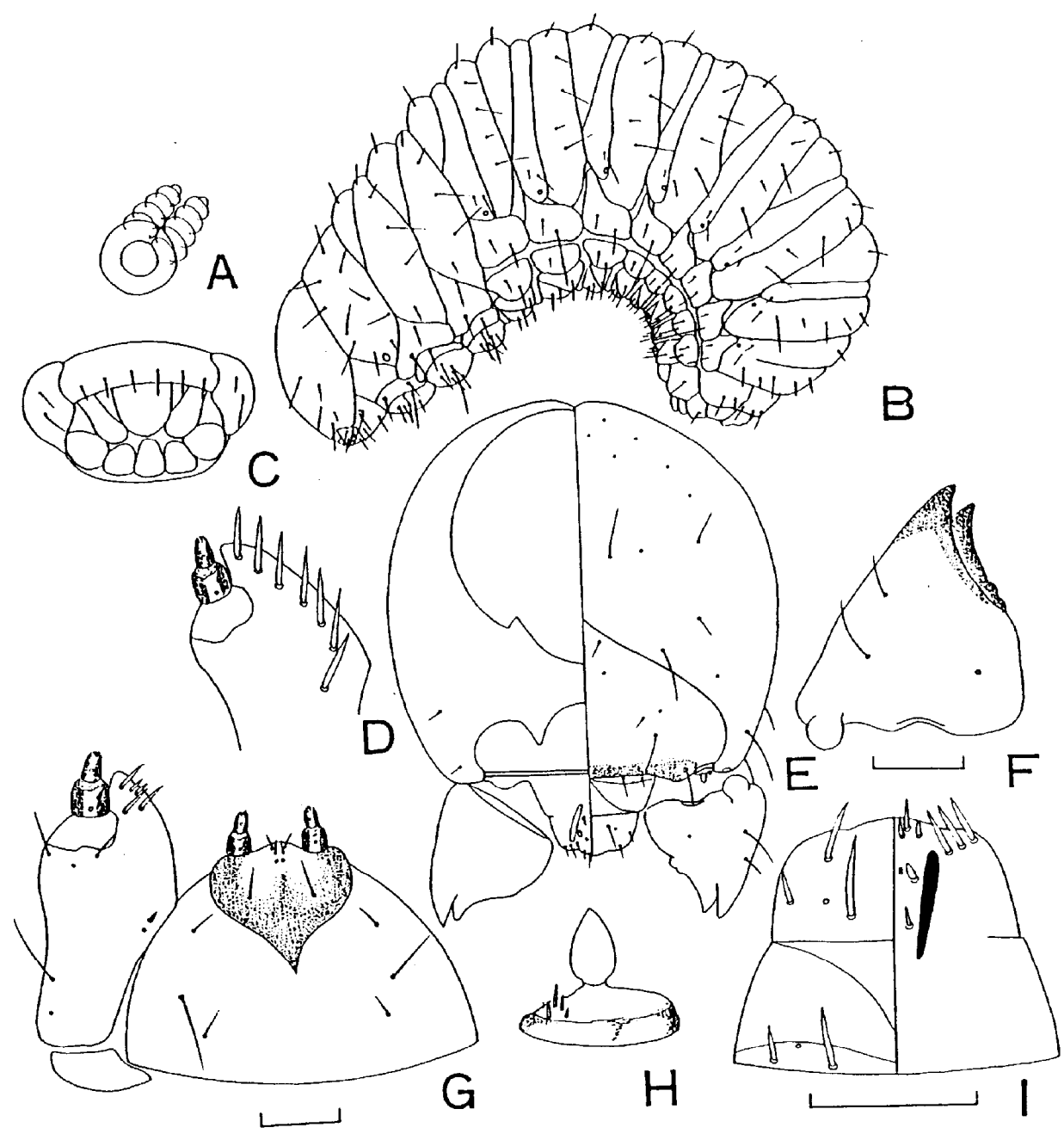

Fig. 9. Derelomus uenoi morimoto

A: Spiracle. B: Mature larva. C: Anus. D: Maxilla, dorsal. E: Head. F: Mandible.

G: Maxilla and labium. H: Antenna. I: Labrum and epipharynx. Scale: $0.1 \mathrm{~mm}$.

\section{Genus Anthonomus Germar}

Anthonomus : Anderson, 1963, Coleopt. Bull., 17: 73. - Ahmad \& Burke, 1972, Misc.

Publ. Ent. Soc. Amer., 8: 44.

\section{Anthonomus bisignifer Schenkling}

(Fig. 10) 
Body nearly circular in cross-section, distinctly curved.

Head free, yellow, broadest behind the middle, slightly wider than long. Anterior ocellus present, posterior ocellus absent. Antenna bearing a subconical segment and four minute setae. Catapophyses in same plane as frons. Hypopharyngeal bracon present.. Endocarina present. Frons with four pairs of setae, setae 1 and 2 short, subequal, 4 and 5 long, subequal, seta 3 absent. Dorsal epicranial setae 1, 3 and 5 long, subequal, seta 2 moderately long, 4 short. Lateral epicranial seta 1 moderately long, 2 long. Ventral epicranial setae short to moderately long, subequal. Four minute posterior epicranial

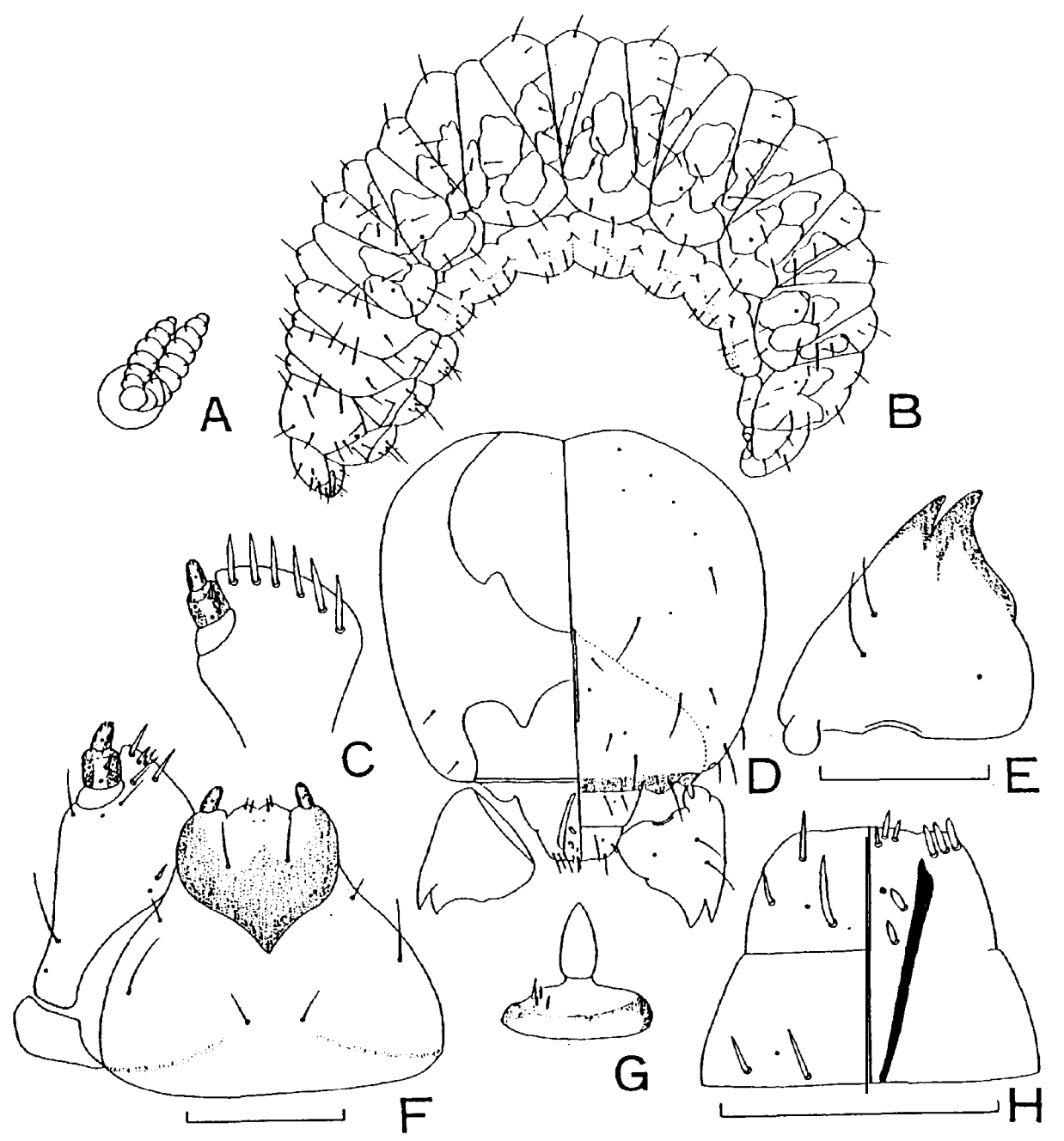

Fig. 10. Anthonomusbisignifer Schenkling

A:Spiracle. B: Mature larva. C: Maxilla, dorsal. D: Head. E: Mandible.

F: Maxilla and labium. G: Antenna. H: Labrum and epipharynx. Scale: O.lmm. 
setae present. Clypeal seta 1 short to moderately long, nearly twice as long as 2 . Anterior margin of labrum weakly trilobed. Labral setae 1 and 2 short to moderately long, nearly twice as long as 3. Paired lateral sensilla present on labrum. Labral rods moderately elongate, stout, subparallel. Epipharynx with three anterolateral setae on an obliquely backward line towards the middle, six anteromedian setae and four median spines. Epipharyngeal sensory pores in two clusters, three in each cluster, before the anterior spines. Mandible stout, bifid at tip. Mandibular setal about equal to and almost directly behind seta 2. Labial palpus with one segment, longer than wide. Premental sclerite showing a distinct posteromedian prejection. Postmentum with three pairs of setae, posterior pair separated by a distance approximately one-half as great as that between setae of middle pair. Maxillary palpus with two segments, basal segment with two sensilla and one very short seta, apical segment without seta. Mala with five ventral and six dorsal setae.

Pronotum with nine setae. Thoracic spiracle bicameral. Prodorsum of meso- and metathorax with a seta. Postdorsum of meso- and metathorax with a seta. Postdorsum of meso- and metathorax with five setae, setae 1, 3 and 5 moderately long, subequal, seta 2 and 4 short, subequal. Alar area with one short seta. Spiracular area with one short seta. Epipleurum with one seta. Pleurum of prothorax with two setae, of meso- and metathorax with one seta. Pedal area with six setae, one moderately long, the remainder shorter and subequal to short sternal seta. Sternal setae subequal to eusternal setae.

Abdomen with eight pairs of spiracles. Spiracles all lateral, bicameral. Typical segment with three dorsal folds. Prodorsum with one short seta. Postdorum with five setae, setae 1, 3 and 5 long, subequal, 2 and 4 short, subequai. Ninth abdominal segment subconical, with several fine setae on each side. Spiracular area with two setae, seta 1 very short, seta 2 short. Epipleurum with two setae, one short, the other slightly longer. Pleurum with one moderately long seta. Pedal area with one short seta. Eusternum with two very short setae. Anus ventral, subterminal, surrounded by four lobes.

Width of head. $0.5 \mathrm{~mm}$.

Materials examined. Mt. Wakasugi, Fukuoka Pref., 10. v. 1959, from flower-bud of a wild rose.

\section{Genus Curculio Linnaeus}

(Figs. 1 1-12)

Balaninus: Gardner, 1934, Ind. For. Rec., 20: 27.

Body very stout, moderately curved.

Head free, slightly retracted, brown to dark orange, slightly broader than long, broadest at middle. Anterior ocellus present, posterior ocellus absent. Antenna with a conical segment and several minute setae. Catapophyses in same plane as frons. Hypopharyngeal bracon readily discernible. Frontal suture distinguishable throughout its length. Epicranial suture more than one-half as long as head. Endocarina distinct, nearly one-half as long as frons, or indistinct. Frons with five pairs of setae, setae 1, 2 and 3 short, subequal, 4 and 5 long, subequal. Dorsal epicranial setae 1, 3 and 5 long, subequal, 2 moderately long, 4 short. Lateral epicranial seta 1 moderately long, 2 long. Ventral 
epicranial setae short to moderately long, subequal. Four minute posterior epicranial setae present. Clypeal seta 1 short to moderately long, nearly twice as long as 2 . Anterior margin of labrum trilobed. Labral setae 1 and 2 short to moderately long, nearly twice as long as 3. Median and paired lateral sensilla present on labrum. Labral rods moderately short, sometime indistinct. Epipharynx with three anterolateral setae, six anteromedian setae and four median spines. Epipharyngeal sensory pores in two clusters, three in each cluster, near the anterior median spines. Epipharynx without asperities. Mandible with two apical teeth, longer than wide. Mandibular seta 1 short, slightly longer than and

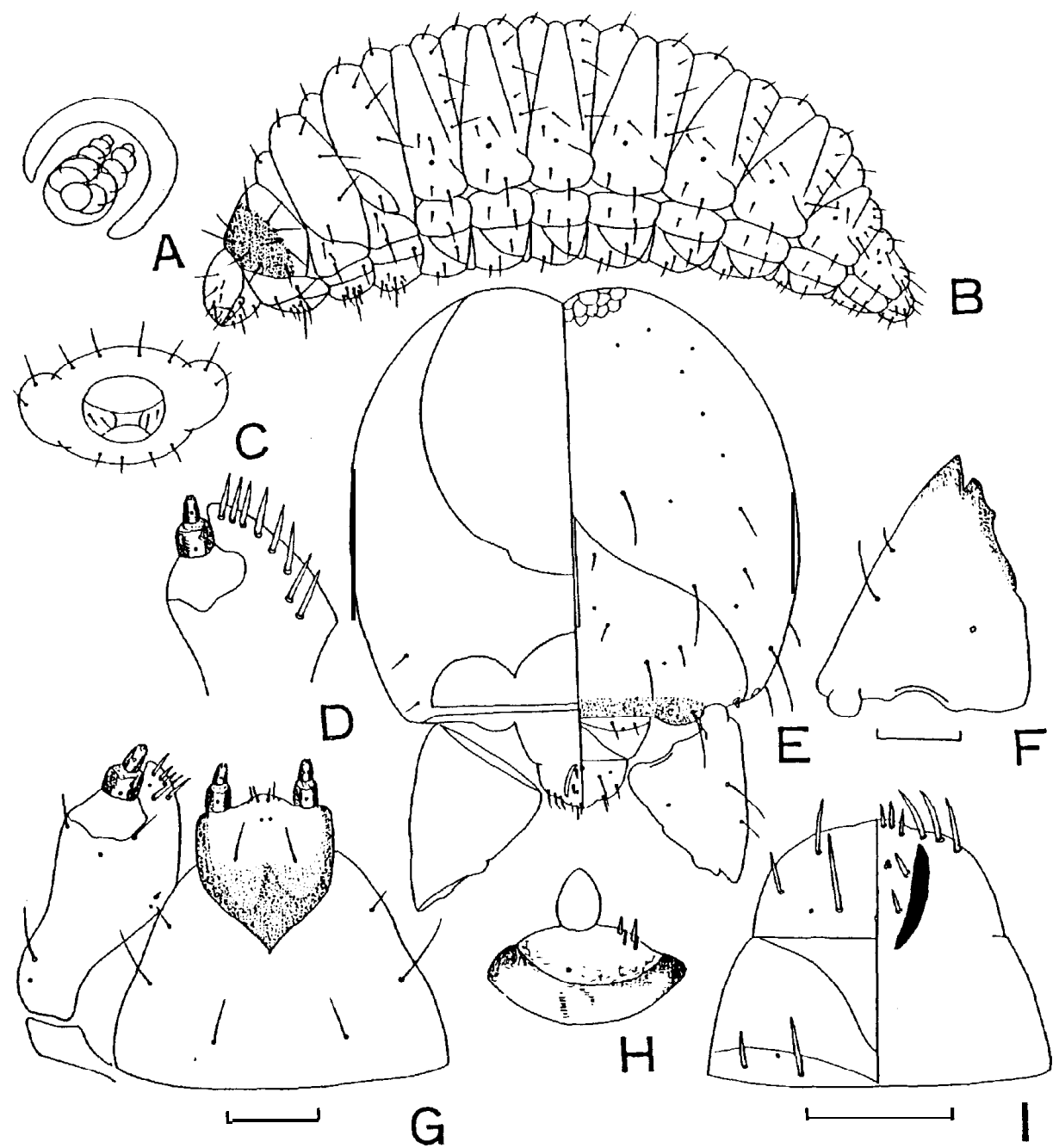

Fig. 11. Curculio sikkimensis Heller (Kuri)

A: Spiracle. B: Mature larva. C: Anus. D: Maxilla, dorsal. E: Head. F: Mandible.

G: Maxilla and labium. H: Antenna. I: Labrum and epipharynx. Scale: $0.2 \mathrm{~mm}$. 


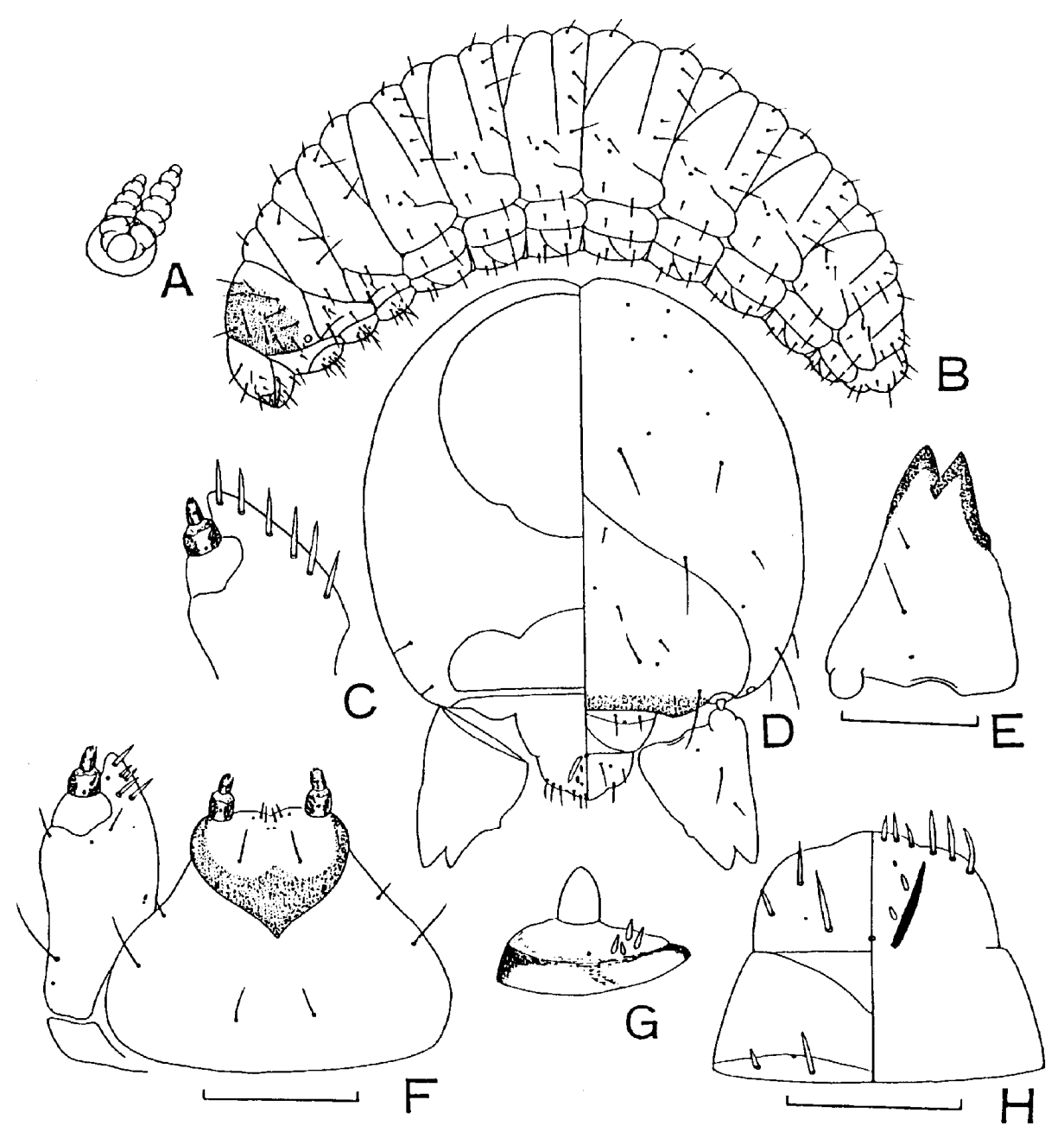

Fig. 12. Curculio parasiticus Morimoto

A: Spiracle. B: Mature larva. C: Maxilla, dorsal. D: Head. E: Mandible.

F: Maxilla and labium. G: Antenna. H: Labrum and epipharynx. scale: $0.1 \mathrm{~mm}$

directly behind 2. Labial palpus with two segments, apical and basal segment longer than wide. Premental sclerite complete, with anterior and posterior median extensions. Postmentum with three pairs of setae, posterior pair separated by a distance approximately one-half as great as that between the middle pair of setae. Maxillary palpi with two segments, the basal segment with two sensilla and one very short lateral seta, apical segment without lateral seta. Mala with five ventral setae of which the median two setae short and situated close to each other, and with five to eight dorsal setae.

Pronotum with ten setae, position and length variable. Thoracic spiracle bicameral. 
Prodorsum of meso- and metathorax with one short seta. Postdorsum of meso- and metathorax with four setae, setae 1 and 2 short, subequal, 3 and 4 long, subequal. Alar area with one short seta. Spiracular area with two setae, one moderately long, one very short. Epipleurum with one seta. Pleurum of prothorax with two setae, of meso- and metathorax with one seta. Pedal area with seven setae, one moderately long, the remainder shorter. Sternal setae subequal to eusternal setae.

Abdomen with eight pairs of spiracles. Spiracles all lateral, bicameral. Typical abdominal segments with three dorsal folds. Prodorsum with one short seta. Postdorsum with five setae, setae 1, 2 and 4 short, subequal, 3 and 5 long, subequal. Spiracular area with two setae, seta 1 very short, seta 2 short. Epipleurum with two setae, one short, the other slightly longer. Pleurum with two setae, one short, the other slightly longer. Pedal area with one short seta. Eusternum with two very short setae. Sternellum present. Anus terminal, X-shaped.

\section{Key to species examied}

1. Endocarina indistinct. Mala with six dorsal setae. Premental sclerite incomplete, apical margin of the sclerite not sharply limited. Frons with a pair of sensilla. Setae of head, thorax and abdomen relatively long ........................ Curculio (Balanobius) pictus

-. Endocarina distinct. Frons with two pairs of sensilla $\ldots \ldots \ldots \ldots \ldots \ldots \ldots . \ldots 2$

2. Mala with five dorsal setae ..................................................... Curculio convexus

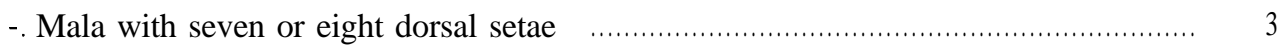

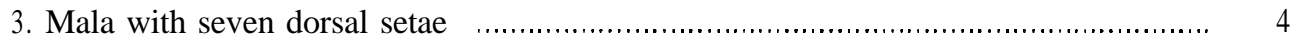

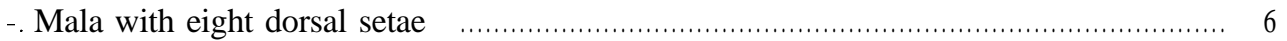

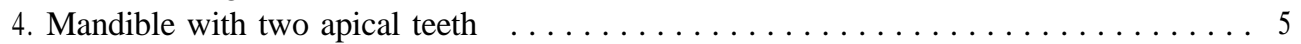

-. Mandible not bifurcate at apex. Ventral setae of mala short .......... Curculio dentipes

5. Labral seta 1 twice as long as 2 or 3 . Ventral setae of mala moderately long. Median knob of cutting edge of mandible distinct ................................. Curculio koreanus

- Labral seta 1 a little longer than 2 or 3 . Median knob of cutting edge of mandible slight Curculio camelliae

6. Mandible with two apical teeth. Frontal seta 3 at the middle between 2 and 4

Curculio styracis

-. Mandible with two apical teeth. Frontal seta 3 near 4 or setae 2-4 situated close to each other

7. Ventral apical tooth of mandible quadrate in ventral view. Frontal setae 2-4 situated close to each other Curculio sikkimensis

-. Each tooth of mandible of the same shape in ventral or dorsal view. Frontal seta 3 situated near 4

8. Mandible slender, median knob of cutting edge less distinct, outer margin with a slight constriction at the middle $\ldots \ldots \ldots \ldots \ldots \ldots \ldots$ Curculio elaeagni -.Mandible stout, median knob of cutting edge distinct, outer margin with three slight constriction Curculio funebris 
Species and materials examined.

Curculio sikkimensis (Heller). Fukuoka City, 22.xi.1957, ex. fruit of Castanea pubinervis. (Fig. 11)

Curculio robustus (Roelofs). Mt. Tachibana, Fukuoka Pref., 16.xi.1976, ex. acorn of Quercus acutissima.

Curculio dentipes (Roleofs). Mt.Tachibana, Fukuoka Pref., 15.xi.1976, ex. acorn of Quercus serrata.

Curculio hilgendorfi (Harold). Mt. Tachibana, Fukuoka Pref., 15 xi.1976, ex. acorn of Castanopsis cuspidata.

Curculio camelliae (Roelofs). Mt. Hikosan, Fukuoka Pref., 6. ix.1957, ex. fruit of Camellia japonica.

Curculio styracis (Roelofs). Mt. Hikosan, Fukuoka Pref., 6.ix. 1957, ex. seed of Styrax japonica.

Curculio funebris (Roelofs). Mt. Tachibana, Fukuoka Pref., 25.vii.1975, ex. fruit of Ficus erecta.

Curculio convexus (Roelofs). Minami Park, Fukuoka City, 1 1.ix.1958, ex. fruit of Viburunum japonica and erosum.

Curculio elaeagni Morimoto. Mt. Hiko, Fukuoka Pref., vi.1962. ex. seed of Elaeagnus multiflora

Curculio koreanus (Heller). Sapporo, 1959, ex. gall on Quercus acutiassima made by a cynipid wasp.

Curculio (Balanobius) pictus (Roelofs). Matsuyama City, 14.vii.1957, ex. gall on Quercus sp. made by a cynipid wasp.

Curculio (Balanobius) parasiticus Morimoto. Ashoro, Hokkaido, 26. vii. 1959, ex. gall on leaves of willow made by a tenthrenidid sawfly. (Fig.12) 